\title{
Emerging Research Areas in Business and Information Systems Engineering
}

\author{
DOI 10.1007/s12599-013-0309-x
}

\section{The Authors}

\author{
Prof. Dr. Martin Bichler ( $\varangle$ ) \\ Decision Sciences \& Systems \\ Department of Informatics \\ TU München \\ Boltzmannstraße 3 \\ 85748 Munich \\ Germany \\ bichler@in.tum.de
}

Prof. Dr. Thomas Hess

Institute for Information Systems

and New Media

LMU Munich

Ludwigstraße 28

80539 Munich

Germany

thess@bwl.Imu.de

Prof. Ramayya Krishnan, Ph.D.

Management Science

and Information Systems

The Heinz College

Carnegie Mellon University

5000 Forbes Avenue

Pittsburgh, PA 15213-3890

USA

rk2x@cmu.edu

\section{Prof. Dr. Peter Loos}

IWi at DFKI

Saarland University

Stuhlsatzenhausweg 3

66123 Saarbrücken

Germany

loos@iwi.uni-sb.de

Published online: 2014-01-04

This article is also available in German in print and via http://www. wirtschaftsinformatik.de: Bichler $M$, Hess T, Krishnan R, Loos P (2013) Aktuelle Forschungsfelder der Wirtschaftsinformatik. WIRTSCHAFTSINFORMATIK. doi: 10.1007/s11576-0130401-3.

(C) Springer Fachmedien Wiesbaden 2014
"What is Business and Information Systems Engineering all about?". "What are key research questions BISE scholars are working on now and in the near future?". These types of questions are being asked increasingly by younger colleagues and students.

The BISE journal publishes research that examines problems in the design, implementation, and management of information systems, as well as their impact on individuals, organizations, industries or society. It provides a platform for established, but also for evolving and new research streams at the intersection of management studies, economics, computer science, and information technology. Within this broad profile, there is a fairly established set of BISE sub-communities each of which has its own research topics and accepted methods and quality standards. Not many colleagues have an overview of ongoing research topics which are at the core of all the sub-communities.

The objective of this special focus issue is to focus attention on new research topics that have emerged which are likely to become very influential in our research community and in business. Since BISE is technology driven, the context and source of these research questions is the rapidly changing technological context enabled by the near ubiquitous adoption of the Internet in Society and by Business. Last year the BISE journal, the Section "Information Systems" (Wirtschaftsinformatik, WKWI) of the German Academic Association for Business Research, and the Special Interest Group "Business Informatics" (GI-FB Wirtschaftsinformatik) of the Gesellschaft für Informatik e. V. organized this special focus issue to initiate a discussion in the BISE community on current and emerging research areas in BISE. The goal of this special focus issue was to publish forward-looking research notes on important topics and phenomena that are likely to frame or expand an important research agenda in the next few years. Apart from this general goal, the special focus issue has dual purpose. First, it should provide an overview of ongoing research streams in our community. These streams should already have shown some initial results, but at the same time bear promise for future high-impact results. Second, it should provide incentives for researchers to work together and discuss topics of joint interest. Actually, most submissions were co-authored by a larger number of authors working in a field.

We were fortunate to receive 39 abstracts on our initial call for papers. The reviews throughout were provided by an outstanding set of national and international senior scholars. A subset of the authors was invited for full paper submissions, where we believed they meet the right level of abstraction and satisfy the requirements specified in the call for papers. In two rounds of reviews, the selection was narrowed down to eight research notes which are published in this special focus issue. A small number of additional research notes from this call for papers will appear in later issues of our journal. The papers published in this special focus issue span a variety of topics:

"Information Systems for 'Wicked Problems' - Research at the Intersection of Social Media and Collective Intelligence" by Schoder et al. focus on Collective Intelligence. This stream of research analyzes how people and computers can be connected so that collectively they act more intelligently than individually. This is area has received substantial attention in the recent years due to the wide-spread use of Wikipedia, YouTube, Twitter, or GitHub.

"Shaping the Next Incarnation of Business Intelligence - Towards a Flexibly Governed Network of Information Integration and Analysis Capabilities" by Felden et al. lay out a vision of business intelligence in which distributed data integration and analysis resources from heterogeneous sources can be brought together to provide organizations with new sensing capabilities. The paper is based on a review of more than 1,000 recent publications in this field.

"Model-Based Decision Support in Manufacturing and Service Networks" by Mönch et al. describes new research topics in an established field of BISE: decision support systems. These topics include integration issues taking into account the autonomy of the 
decision making entities in face of information asymmetry, the modeling of preferences of the decision makers, efficiently determining robust solutions, and a reduction of the time needed for model building and usage.

"Energy Informatics - Current and Future Research Directions" by Goebel et al. discusses research on (i) the increase of energy efficiency and (ii) on the efficient integration of renewable sources of energy by making power systems smarter. Energy security is arguably one of the key challenges for society and the article describes a framework how BISE and related disciplines can help addressing this problem.

"Evolutionary Business Information Systems - Perspectives and Challenges of an Emerging Class of Information Systems" by Neumann et al. describes challenges in IS engineering regarding the evolution of large business information systems. Many new trends in software engineering concepts and information technology allow designing and developing systems which allow for an evolution based on changing needs of the various stakeholders.

"The Research Field "Modeling Business Information Systems" - Current Challenges and Basic Points of a Future Research Agenda" by Strecker et al. provides an overview of new challenges in another established field of BISE research which had significant impact on practice: information systems modeling. The authors discuss new phenomena to be modeled, as well as new modeling languages and tools.

"Business Models - An Information Systems Research Agenda" by Veit et al. in contrast is again a rather new topic trying to understand underlying concepts of successful business models as a link between business strategy and processes. The authors discuss business models in IT industries, IT enabled or digital business models, and IT support for developing and managing business models.

"User, Use \& Utility Research - The Digital User as New Design Perspective in Business and Information Systems Engineering" by Uebernickel et al. discusses trends in BISE on a more strategic level. They emphasize the impact information systems nowadays on all our lives every day and the role that the users can play in developing and influencing the shape of these information systems.

Of course, a special focus issue like this cannot cover all relevant research streams in BISE. For a few established fields in BISE we did not get submissions. Some authors might just not have found time to submit an article, some proposals were rejected because the reviewers felt that they are either to narrow or out of scope of this special focus issue. Nevertheless, the special focus issue covers a great variety of research topics also emphasizing the interdisciplinary nature of our field.

In a broad community such as BISE, everybody will have favorites, like some proposals and dislike others. Overall, however, we believe that the reviewing process led to a fine set of research notes providing an up-to-date view of important research areas in our community. We hope that the articles will provide a basis for fruitful discussions and that they provide ideas for others in selecting their next research projects. We would like to thank the reviewers as well as all the contributors for their hard work. In addition, we would like to thank Deutsche Bank, McKinsey\&Company and SAP for their continued support for the journal and hope you will enjoy reading the special focus issue. 